\title{
Detection of IgG1 and IgG4 subtypes reactive against potato apyrase in schistosomiasis patients
}

\author{
Priscila de Faria-Pinto, ${ }^{1,2}$, Rita Gabriela Pedrosa Ribeiro Mendes ${ }^{1}$, \\ Cristiane de Carvalho-Campos ${ }^{1}$, Ana Carolina Ribeiro Gomes Maia', \\ Áureo Almeida Oliveira², Paulo Marcos Zech Coelho ${ }^{2,3}$, Eveline Gomes Vasconcelos¹/+
}

\author{
${ }^{1}$ Departamento de Bioquímica, Instituto de Ciências Biológicas, Laboratório de Estrutura e Função de Proteínas, \\ Universidade Federal de Juiz de Fora, 36036-330 Juiz de Fora, MG, Brasil 'Instituto de Pesquisas René Rachou-Fiocruz, \\ Belo Horizonte, MG, Brasil ${ }^{3}$ Santa Casa de Belo Horizonte, Belo Horizonte, MG, Brasil
}

In this paper, we showed for the first time that the conserved domains within Schistosoma mansoni ATP diphosphohydrolase isoforms, shared with potato apyrase, possess epitopes for the IgG1 and IgG4 subtypes, as 24 (80\%) of the 30 schistosomiasis patients were seropositive for this vegetable protein. The analyses for each patient cured $(n=14)$ after treatment $(A T)$ with praziquantel revealed variable IgGl and IgG4 reactivity against potato apyrase. Different antigenic epitopes shared between the vegetable and parasite proteins could be involved in susceptibility or resistance to $\mathrm{S}$. mansoni AT with praziquantel and these possibilities should be explored.

Key words: Schistosoma mansoni - ATP diphosphohydrolase - potato apyrase

A membrane-associated ATP diphosphohydrolase isoform was identified on the surface of Schistosoma manso$n i$ adult worm and schistosomule (Vasconcelos et al. 1993, 1996, DeMarco et al. 2003). Transcriptome and proteomic analyses identified this protein as a potential drug target and vaccine candidate (Oliveira et al. 2008). Recently, the gene of another S. mansoni ATP diphosphohydrolase isoform was reported and its soluble protein form was demonstrated to be secreted from the adult worm tegument (Levano-Garcia et al. 2007, Oliveira et al. 2008). Egg-derived antigens have also been intensively investigated (Kusel et al. 2007) and both membrane-associated and soluble ATP diphosphohydrolase isoforms have been identified in S. mansoni eggs (Faria-Pinto et al. 2004).

The antigenicity of native $S$. mansoni ATP diphosphohydrolase isoforms have been recently described (Faria-Pinto et al. 2004). In addition, cross-immunoreactivity between potato apyrase and total $\mathrm{IgG}$ antibody from S. mansoni-infected mice or schistosomiasis patients strongly suggested that the epitopes shared between the vegetable protein and $S$. mansoni ATP diphosphohydrolase isoforms are antigenic (Faria-Pinto et al. 2004, 2008). IgG1 and IgG4 antibody reactivity against specific antigens have been involved in resistance or susceptibility to $S$. mansoni re-infection (Corrêa-Oliveira et al. 2000). In an attempt to detect the potential of the epitopes shared between vegetable and parasite proteins in studies of schistosomiasis, we analysed the re-

Financial support: FAPEMIG, CNPq, CPqRR (to PFP), PIBIC, PROBIC, BIC/UFJF, CAPES (to RGPR, CCC, ACRGM)

+Corresponding author: eveline.vasconcelos@ufjf.edu.br

Received 5 December 2008

Accepted 18 December 2009 activity of these isotypes against potato apyrase, before and after chemotherapeutic cure. For the pre-treatment, we only selected patients with schistosomiasis from an endemic area, most of whom exhibited a low intensity of infection. Patients co-infected with other parasites were excluded from this study. After treatment (AT), only the antibody reactivities of patients that had a clear demonstration of chemotherapeutic cure, with no other parasites present in their parasitological stools, were included in this study.

The serum samples of patients with schistomiasis (n = 49) were selected from a collection of samples from Penha do Cassiano, in the state of Minas Gerais (MG), Brazil, an area endemic for S. mansoni that is studied by the Schistosomiasis Laboratory of the Instituto de Pesquisas René Rachou (CPqRR), Belo Horizonte, MG, Brazil. The patients (age range 4-83 years) were diagnosed by positive quantitative parasitological stool examinations by the Kato-Katz method (Table). Blood was obtained by venipuncture before and six months AT with praziquantel $(40 \mathrm{mg} / \mathrm{kg}$ of body weight for adults and children). Six to nine selected sera from healthy individuals from an area non-endemic for schistosomiasis were used as controls. The study protocols were approved by the Ethical Committee for Human Research of CPqRR under protocol CEPSH/CPqRR 04/2005.

Potato apyrase was purified from a commercial strain of Solanum tuberosum (Faria-Pinto et al. 2004). The total $\mathrm{IgG}, \mathrm{IgGl}$ and $\mathrm{IgG} 4$ antibody reactivities against potato apyrase were evaluated by ELISA, using potato apyrase $(5 \mu \mathrm{g})$ as coating antigens and serum samples diluted 1:50-1:400, as previously described (Faria-Pinto et al. 2008), peroxidase-conjugated anti-IgG, anti-IgG1 or anti-IgG4 human-specific immunoglobulin antibodies (PharMingen, Sand Diego, CA) and O-phenylenediamine dihydrochloride $/ \mathrm{H}_{2} \mathrm{O}_{2}$ as the substrate. The total IgG reactivity $(0.246 \pm 0.186)$ for potato apyrase in serum samples diluted 1:200 from 49 schistosomiasis pa- 
TABLE

Characteristics of the patients with schistosomiasis from Penha do Cassiano, Minas Gerais, MG, Brazil

\begin{tabular}{|c|c|c|c|c|}
\hline Group & $\begin{array}{c}\text { Sample size } \\
\text { (female/male) }\end{array}$ & Mean age \pm SD & $\mathrm{EPG} \pm \mathrm{SEM}$ & $\begin{array}{c}\text { Total } \mathrm{IgG}^{a} \\
\text { (seropositivity) } \\
\mathrm{n}(\%)\end{array}$ \\
\hline Children & $15(7 / 8)$ & $12.13 \pm 3.96$ & $112.40 \pm 58.41$ & $\begin{array}{c}0.313 \pm 0.240 \\
10(67) \\
0.217 \pm 0.153\end{array}$ \\
\hline Adults & $34(11 / 23)$ & $38.15 \pm 19.10$ & $185.1 \pm 69.40$ & $20(59)$ \\
\hline
\end{tabular}

$a$ : the result is expressed in optical density and the cut-off is 0.14; EPG: eggs per gram of faeces; SD: standard deviation; SEM: standard error of the mean.

tients from Penha do Cassiano was significantly higher $(\mathrm{p}<0.01)$ than that found in healthy individuals $(0.080$ \pm 0.030 ; cut-off 0.140$)$ and $30(61 \%)$ of them demonstrated seropositivity for this vegetable protein (Fig. 1). Similar IgG reactivities were found between children and adults (Table). Forty-three of the 49 selected patients with schistosomiasis from Penha do Cassiano had a low intensity of infection (Table). Heavy infection (971 \pm 194 eggs per gram of faeces) was found in only six patients and their $\operatorname{IgG}$ reactivity $(0.150 \pm$ 0.064 ) against potato apyrase was statistically similar to that found in patients with a low intensity of infection (Table).

The IgG seropositive patients $(n=30)$ from Penha do Cassiano were selected for analyses of IgG1 and IgG4 antibody reactivity and the representative data for sera diluted 1:50 are shown in Fig. 2. The IgG1 subtype reactivity against potato apyrase in serum samples from schistosomiasis patients $(0.504 \pm 0.527)$ was significantly higher $(\mathrm{p}<0.001)$ than that found in healthy individuals $(0.012 \pm 0.016)$, with $80 \%$ seropositivity (Fig. 2A; $\mathrm{n}=24$; cut-off, 0.044). The IgG4 subtype reactivity against potato apyrase $(0.352 \pm 0.303)$ was significantly higher $(p<0.001)$ than that found in healthy individuals $(0.032 \pm 0.030)$ and, similar to the results observed for IgG1 seropositivity, 24 of the 30 ( $80 \%$; cut-off, 0.122 ) schistosomiasis patients were seropositive for potato apyrase (Fig. 2B). Nineteen (63\%) of the 30 schistosomiasis patients were seropositive for both IgG1 and IgG4 subtypes. Five (17\%) of them were seropositive only for IgG1 and another five (17\%) patients only for the IgG4 subtype. Only one (3\%) schistosomiasis patient, who was IgG seropositive for potato apyrase, demonstrated negative $\mathrm{IgG1}$ and $\mathrm{IgG} 4$ reactivity. These results suggested the reactivity of the $\operatorname{IgG} 2$ and/or IgG3 subtypes, which were not tested in the present study against this vegetable protein.

Six months after chemotherapy, all 30 patients were negative for $S$. mansoni eggs, but other parasites were visualised in 16 of them on parasitologic examination of the faeces and their results were not included in the statistical analyses AT. Therefore, the $\mathrm{IgG1}$ and $\mathrm{IgG} 4$

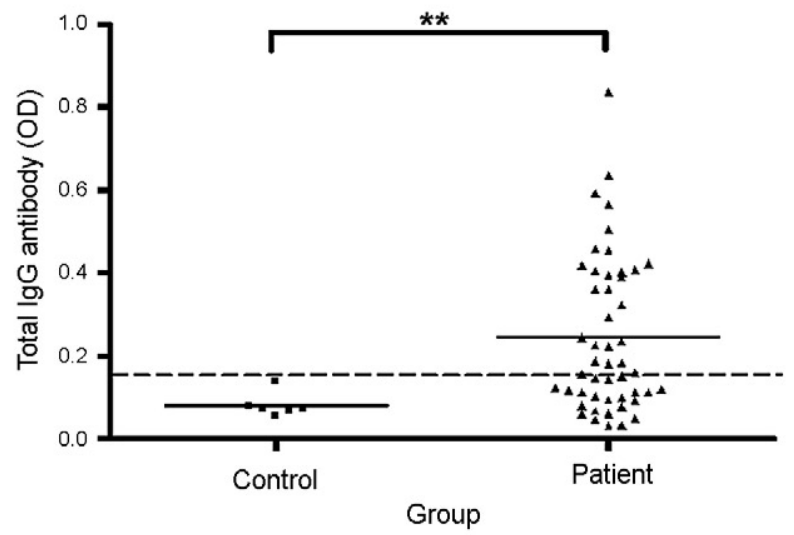

Fig. 1: total IgG antibody reactivity against potato apyrase. The total IgG antibody reactivity was determined by ELISA, using potato apyrase as coating antigen and serum samples diluted 1:200 from healthy individuals (control; $n=6$ ) and schistosomiasis patients $(n=49)$. The results were expressed as absorbance [optical density (OD) $492 \mathrm{~nm}$ ] mean value of duplicate assay. The cut-off was calculated as the mean of the OD of serum samples from healthy individuals plus two standard deviations. Values greater than this cutoff level were considered to be seropositive. The data were analyzed using the Mann-Whitney test. The linear and dotted horizontal lines represent the mean or cutoff value, respectively. Asterisks mean $\mathrm{p}<0.01$.

subtype levels were analysed only in patients who were cured and who showed negative results on parasitologic examination of the faeces $(n=14)$. Taken together (Fig. $2 \mathrm{C}, \mathrm{D})$, no significant difference was observed in their IgG1 [before treatment $(\mathrm{BT})=0.458 \pm 0.533$; $\mathrm{AT}=$ $0.188 \pm 0.220]$ or $\mathrm{IgG} 4(\mathrm{BT}=0.298 \pm 0.227, \mathrm{AT}=0.188$ \pm 0.150 ) subtype levels BT or AT. However, the particular analysis of each patient revealed that IgG1 seropositivity decreased in eight patients and slowly increased in two patients, whereas four of the patients maintained similar levels AT (Fig. 2C). The IgG4 seropositivity decreased in nine patients and slowly increased in three patients, whereas two of the patients maintained similar levels AT (Fig. 2D). 

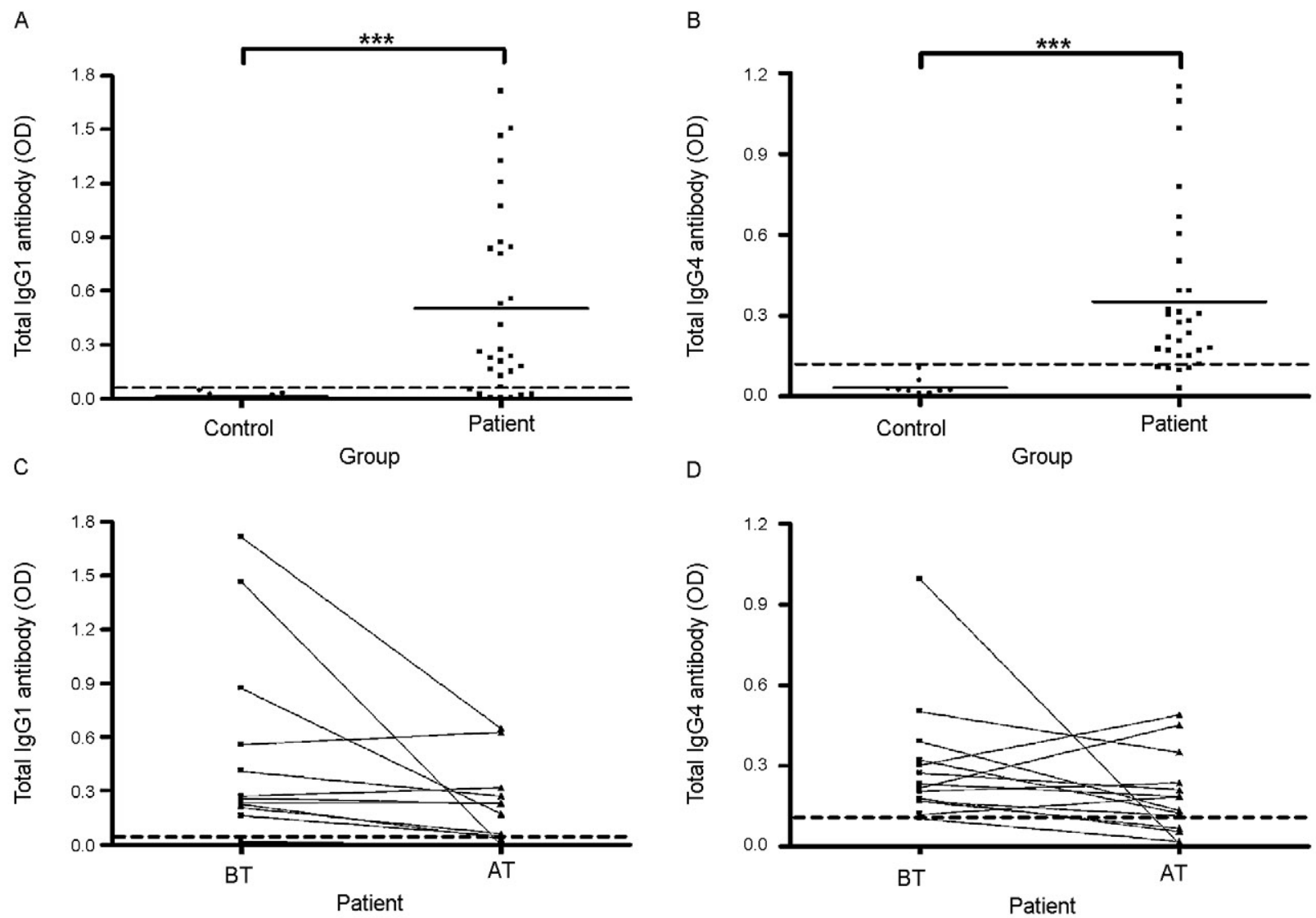

Fig. 2: IgG1 or IgG4 antibody reactivity against potato apyrase. The IgG1 (A, C) or IgG4 (B, D) antibody reactivity was determined by ELISA, using potato apyrase as coating antigen and serum samples diluted 1:50 from healthy individuals (control; $n=9)$ and schistosomiasis patients $(\mathrm{n}=30)$. After treatment (AT) with praziquantel, the antibody levels of 14 cured patients were compared to the results obtained before treatment (BT). The results were expressed as absorbance [optical density (OD) $492 \mathrm{~nm}$ ] mean value of duplicate assay. The cut-off was calculated as the mean of the OD of serum samples from healthy individuals plus two or three standard deviations. Values greater than this cutoff level were considered to be seropositive. The data were analyzed using the Mann-Whitney test. The linear and dotted horizontal lines represent the mean or cut-off value, respectively. Asterisks mean $\mathrm{p}<0.001$.

In this study, we showed for the first time that the conserved domains within S. mansoni ATP diphosphohydrolase isoforms, which are shared with potato apyrase, are recognised by IgG1 and IgG4 subtypes, as 24 $(80 \%)$ of the 30 schistosomiasis patients were seropositive for this vegetable protein.

The IgG1 and IgG4 subtype reactivities of each schistosomiasis patient were variable $\mathrm{BT}$ and $\mathrm{AT}$ and no standard humoral immune response was observed among them. In schistosomiasis, protective immunity against infection with $S$. mansoni has been related to the development of both humoral and cellular immune responses. Analyses of antibody responses to specific antigens demonstrated high IgG2 and IgG4 antibody levels associated with the slow development of immunity to $S$. mansoni re-infection AT. In contrast, individuals who were resistant to $S$. mansoni infection and re-infection and living in schistosomiasis endemic areas, produced high levels of IgG1 and IgG3 antibodies and the results were correlated with parasite elimination (Corrêa-Oliveira et al. 2000,
Mutapi 2001, Kusel et al. 2007). These variations in humoral responses between different individuals could be explained by age, sex, nutrition, parasite load and/or host genetic factors (Mutapi 2001).

S. mansoni ATP diphosphohydrolase was characterised in soluble egg antigens (Faria-Pinto et al. 2004). Recently, using in silico analysis, we showed that potato apyrase and parasites ATP diphosphohydrolase isoforms, which are members of the same proteins family, have domains shared among them that are predicted to be rich in B-cell epitopes (Faria-Pinto et al. 2008, Vasconcelos et al. 2009). We hypothesised that different antigenic epitopes shared between potato apyrase and S. mansoni ATP diphosphohydrolase isoforms could be involved in susceptibility or resistance to $S$. mansoni AT. The reactivities of IgG subtypes to potato apyrase, or to synthetic peptides belonging to these conserved domains, could be studied in larger populations from S. mansoni endemic areas to test their potentiality in epidemiologic studies, before and after chemotherapy. 


\section{REFERENCES}

Corrêa-Oliveira R, Rodrigues Caldas I, Martins-Filho OA, Carvalho Queiroz C, Lambertucci JR, Renan Cunha-Melo J, Soares Silveira A, Prata A, Wilson A, Gazzinelli G 2000. Analysis of the effects of treatment of human Schistosoma mansoni infection on the immune response of patients from endemic areas. Acta Trop 77: $141-146$

DeMarco R, Kowaltowski AT, Mortara RA, Verjovski-Almeida S 2003. Molecular characterization and immunolocalization of Schistosoma mansoni ATP-diphosphohydrolase. Biochem Biophys Res Commun 307: 831-838.

Faria-Pinto P, Meirelles MN, Lenzi HL, Mota EM, Penido ML, Coelho PM, Vasconcelos EG 2004. ATP diphosphohydrolase from Schistosoma mansoni egg: characterization and immunocytochemical localization of a new antigen. Parasitology 129: 51-57.

Faria-Pinto P, Rezende-Soares FA, Molica AM, Montesano MA, Marques MJ, Rocha MO, Gomes JA, Enk MJ, Correa-Oliveira R, Coelho PM, Neto SM, Franco OL, Vasconcelos EG 2008. Mapping of the conserved antigenic domains shared between potato apyrase and parasite ATP diphosphohydrolases: potential application in human parasitic diseases. Parasitology 135: 943-953.

Kusel JR, Al-Adhami BH, Doenhoff MJ 2007. The schistosome in the mammalian host: understanding the mechanisms of adaptation. Parasitology 134: 1477-1526.
Levano-Garcia J, Mortara RA, Verjovski-Almeida S, DeMarco R 2007. Characterization of Schistosoma mansoni ATPDase2 gene, a novel apyrase family member. Biochem Biophys Res Commun 352: 384-389.

Mutapi F 2001. Heterogeneities in anti-schistosome humoral responses following chemotherapy. Trends Parasitol 17: 518-524.

Oliveira SC, Fonseca CT, Cardoso FC, Farias LP, Leite LC 2008. Recent advances in vaccine research against schistosomiasis in Brazil. Acta Trop 108: 256-262.

Vasconcelos EG, Faria-Pinto P, Rezende-Soares FA, Penido ML, Gonçalves-da-Costa SC, Coelho PM 2009. Potato apyrase: a new tool for parasitic disease research. In P Tennant, N Benkeblia (eds.), Potato II. Fruit, vegetable and cereal science and biotechnology 3 (special issue 1): 80-88.

Vasconcelos EG, Ferreira ST, Carvalho TM, Souza W, Kettlun AM, Mancilla M, Valenzuela MA, Verjovski-Almeida S 1996. Partial purification and immunohistochemical localization of ATP diphosphohydrolase from Schistosoma mansoni. Immunological cross-reactivities with potato apyrase and Toxoplasma gondii nucleoside triphosphate hydrolase. J Biol Chem 271: 22139-22145.

Vasconcelos EG, Nascimento PS, Meirelles MN, Verjovski-Almeida S, Ferreira ST 1993. Characterization and localization of an ATPdiphosphohydrolase on the external surface of the tegument of Schistosoma mansoni. Mol Biochem Parasitol 58: 205-214. 